RESUMEN: La intención moralizante de la obra historiográfica del latino Tácito, los "Anales", es innegable. En el presente analizamos y contextualizamos su propósito edificador a partir de las aparentes $\mathrm{y}$ de las verdaderas descalificaciones que hizo recaer sobre ciertas mujeres, en tanto mujeres, y sobre ciertos hombres, en tanto hombres. Teniendo como una conclusión subrayar el optimismo, en el ámbito moral-social, como característica de la obra de Tácito.

PALABRAS CLAVE: Historiografía, Roma, género, moral, historia social.

RECEPCIÓN: 20 de agosto de 2016.

ACEPTACIÓN: 9 de abril de 2018.
DISQUALIFICATIONS AND TEACHINGS OF GENDER IN THE ANNALS OF CORNELIO TACITUS

ABSTRACT: The moralizing intention of the historiographical work of the Latin Tacitus, the "Annals", is undeniable. I analyze and contextualize its edifying purpose from the apparent and true disqualifications that made fall on certain women, as women, and on certain men, as men. I have as a conclusion to emphasize the optimism, in the moral-social field, as characteristic of the work of Tacitus.

KEYWORDS: Historiography, Rome, gender, moral, social history.

*Doctorando en Humanidades, en el área de Filosofía Política, por la Universidad Autónoma Metropolitana. 


\section{DESCALIFICACIONES Y ENSEÑANZAS DE GÉNERO EN LOS ANALES DE CORNELIO TÁCITO}

$\mathrm{M}$ ichel de Montaigne (1533-1592) y Edward Gibbon (1737-1794) consideraban al historiador Tácito (55-120 d.C.) como un erudito que escribió sobre el pasado con una intención filosófica y moralizante. ${ }^{1}$ En estas opiniones estamos de acuerdo: el conjunto de historias que nos entrega están llenas de descripciones sobre las pasiones, deseos, excesos, equivocaciones $\mathrm{y}$, cómo no, de las virtudes de los romanos. Tácito tuvo la intención de que los romanos aprendieran (de los personajes ilustres) del pasado para evitar comportarse equivocadamente, ${ }^{2}$ al menos a nivel personal y moral.

${ }^{1}$ John Burrow, Historia de las historias, 2009, Barcelona, Crítica, trad. de Ferrán Meler Ortí, p. 161.

${ }^{2}$ Flavia Florentino Varella, "Sine ira et studio: retórica, tempo e verdade na historiografía de Tácito", História da Historiografia, núm. 1 (2008), p. 71.
Aquí trataré de mostrar, a partir de presupuestos anteriores (Gibbon, Montaigne, Burrow, Florentino, y otros), que las críticas de Tácito hacia los hechos innobles, deleznables e inmorales de los personajes del pasado, se dirigen con la misma fuerza tanto a los realizados por hombres, en tanto miembros del género masculino, como a los realizados por mujeres, en tanto mujeres. Sus críticas tenían, pues, el objetivo de enseñar a comportarse correctamente tanto a los hombres (en tanto hombres) como a las mujeres (en tanto mujeres). 


\section{¿Acusaciones e insultos contra las mujeres?}

Estamos plenamente de acuerdo con investigadores como Mary R. $\mathrm{McHugh}$ en que no hay que tratar los comentarios de Tácito sobre diversas mujeres como completamente hostiles hacia ellas, no hay que calificar sus comentarios en términos absolutos, pues él "pintó sus retratos en tonos de gris, entendiendo la complejidad de la naturaleza humana y apreciando que la mayoría de los personajes, hombres y mujeres, tienen su parte de virtudes y vicios". ${ }^{3}$ Por lo que a continuación trataré de mostrar que, con cierta seguridad, no todas las descalificaciones, reproches o insultos de un autor antiguo contra una mujer son eso en realidad. Y si se hace referencia a ciertas cualidades de un personaje femenino siempre será para edificar.

En los Anales, Livia, la madre del emperador Tiberio, tiene una gran influencia en él, la cabeza del Imperio. Desde el comienzo de su matrimonio con Octavio Augusto, Livia se había marcado la meta de mostrarse como ejemplo de virtud ante los demás, ${ }^{4}$ esto seguramente le agradó al emperador y fue un arma contra sus detractores, incluyendo a los historiadores que fueron enemigos de ella.

${ }^{3}$ Mary McHugh, "Ferox femina Agrippina Maior in Tacitus' Annales", Helios 39/1 (2012), p. 74.

${ }^{4}$ Matthew Dennison, Livia, Empress of Rome: A Biography, 2011, Nueva York, St. Martin's Press, p. 80 .
Sobre tal personaje femenino nos dice Tácito: "Livia, dura [gravis] madre para la república, dura [gravis] madrastra para la casa de los Césares" (Tac. Ann., 1, 10, 5). ¿ ¿Y qué puede significar aquí gravis? Puede significar, independientemente del contexto, "pesada", "grande", "alta", "excesiva", "grave", "preñada", "poderosa”, "importante", "rigurosa", "penosa", "insoportable", "enfadosa", "acabada", "débil" o "agobiada", 6 es decir, podemos ver que no todas las acepciones de la palabra poseen connotación negativa. El afirmar que Livia fue gravis puede ser hasta un elogio.

Mary McHugh ha demostrado con efectividad que Tácito habló de Julia Agripina (15-59 d.C.), como de una persona que carecía de una debilidad "femenina", debido a que ella poseía una ambición "masculina". Aunque aquí se habla en términos de género, la "debilidad" o la "ambición" que posee Agripina no significan, no precisamente, calificativos hostiles hacia ella por parte de Tácito sino, por el contrario, se puede tratar de elogios; esto por tener el comportamiento tradicional esperado de los miembros masculinos de la clase senatorial así como de las matronas romanas. Agripina es quizá elogiada en tanto

${ }^{5}$ Tácito, Anales Libros I-II, 2009, México, UNAM, trad. de José Tapia Zúñiga.

${ }^{6}$ Julio Pimentel Álvarez, Diccionario LatínEspañol Español-Latín, 2004, México, Porrúa, p. 322. 
que con frecuencia se comportaba de manera feroz, ferox. ${ }^{7}$

La historiadora Judith Ginsburg nos hace ver incluso que Tácito coloca a la muerte de Silano, maquinada por Agripina, como el primer evento del reinado de Nerón, para así evidenciar el carácter violento y ambicioso de la emperatriz. ${ }^{8}$ Aunque tal asesinato también se puede tratar de un comportamiento o acto en gran manera justificado, sin vinculación con alguna falta por parte de Agripina: Silano tenía sangre de Augusto y podía ser un rival al trono para el hijo de Agripina, para Nerón.

Otro pasaje en el que Tácito parece hablar de Agripina de manera despectiva (pero que considero que no es así) es el siguiente: "Bramaba Agripina de haber de sufrir el tener por émula a una liberta, y por nuera a una esclava, y de semejantes consideraciones mujeriles" (Tac. Ann., 13, 13, 1). ${ }^{9}$ Evidentemente Agripina no quiere tener por imitadora a una liberta, pues era una clase mal vista. De esta circunstancia no se puede decir que estemos ante un prejuicio o una fijación por parte de ella sino que, el que Tácito hable de las "consideraciones mujeriles" (muliebriter) de la emperatriz puede hasta ser otro

${ }^{7}$ Mary McHugh, op. cit.

${ }^{8}$ Judith Ginsburgh, Representing Agrippina: Constructions of female power in the early roman empire, 2006, Oxford, Oxford University Press, p. 36.

${ }^{9}$ Tácito, Anales, 1975, México, Porrúa, trad. de Carlos Coloma. elogio: pues, en Anales XIII, 3, Tácito no habla del recelo caprichoso y "mujeril" de una específica mujer poderosa contra una exesclava, sino del prejuicio generalizado de los patricios (hombres y mujeres) contra los libertos: "muchos libertos, ante los ojos de los latinos, no eran sino hombres del pueblo, pobres y despreciables". ${ }^{10}$ Una enseñanza que debían de seguir todos los patricios.

Es probable que, por causa de su sentido del deber (y de clase), Agripina haya considerado insufrible tener por imitadora, aemulus, a una liberta. Para comprender lo anterior hay que contextualizar aún más: existía la idea generalizada, en tiempos imperiales, de que los que habían sido manumitidos no sabían vivir como libres (los libertos del Satiricón de Petronio son buenos ejemplos ficticios de ello). Agripina no quería ser un ejemplo de un tipo de persona que ni siquiera sabía cómo vivir en libertad (siendo que algunos aristócratas romanos hasta habían propugnado leyes para que en ciertos casos los libertos volvieran a la esclavitud pues para los primeros no se merecían la libertad; algunos propusieron que al menos se les quitara la ciudadanía romana si tenían actitudes ingratas o deshonorables una vez manumitidos). Agripina intentaba cumplir el deber patricio

${ }^{10}$ Jean Andreu, "El liberto", en El hombre romano, 1989, Madrid, Alianza, trad. de Jimena Castaño Vejarano, p. 207. 
de distinguirse sobre los otros sectores poblacionales, en especial de distinguirse de los que alguna vez habían sido esclavos. Y el evitar ser imitada por una liberta, como evitar ser la suegra de una esclava, podían, creo, ser buenas y elogiosas actividades aristocráticas de índole tanto "femenina" como "masculina".

En Tácito no solo encontramos pasajes que tienen cierta ambigüedad en referencia a la cualidad de las mujeres en tanto mujeres sino que también encontramos tanto ataques como diáfanos elogios y cumplidos hacia las mujeres. Y estos últimos son elogios que reflejan la opinión personal del estudioso, su afán de poner el ejemplo a sus lectores a partir de casos encomiables. Un dechado de esto último es la defensa de Paulina (m. 65 d.C.), esposa del filósofo Séneca (4 a.C.65 d.C.), quien, al parecer de Tácito, fue víctima de la siempre malintencionada opinión pública (Tac. Ann., 15, 64, 2-5). ${ }^{11}$

Varios de los estudios modernos en torno a los personajes femeninos de la historiografía taciteana se enfocan, por buenas razones, en las "villanas": Mesalina (25-48 d.C.) o Agripina. Esto es comprensible en tanto que estos personajes tienen un mayor protagonismo, dentro de la obra taciteana, que otras féminas. La razón de ese protagonismo radica en que, insistimos, a través de la crítica a

\footnotetext{
${ }^{11}$ Tácito, Anales.
}

aquellas tres conspicuas mujeres "perversas", Tácito trataba de edificar a sus lectores/oyentes, a la sociedad romana en general.

Nuestro historiador (como vemos en los Anales 15, 64) elogió las acciones dignas de las mujeres (de la misma forma que elogió las acciones dignas de los varones), y cuando ataca a las mujeres que cometen actos indignos, lo hace con el propósito de educar a sus lectores del futuro. ${ }^{12} \mathrm{Y}$ este propósito apuntaba tanto a los varones como a las féminas. Además, hay que tener en cuenta que los varones romanos deseaban que sus esposas, hijas o hermanas fueran un dechado de la virtud femenina. ${ }^{13}$ Como bien señala Sarah Fernandes, ${ }^{14}$ los personajes femeninos son empleados por Tácito como recursos retóricos, son empleados como exempla de correctas o incorrectas acciones; y aún es trabajo de los investigadores averiguar con certeza cuándo nuestro historiador está hablando de un acto correcto y cuándo de uno incorrecto.

Así, en el mencionado personaje de Paulina encontramos, entre tantos personajes viciosos e indignos, un dechado de rectitud. No es un caso ais-

${ }^{12}$ Florentino Varella, "Sine ira et studio, p. 79.

${ }^{13}$ Claudia Beltrão Da Rosa, "Magna mater, Claudia Quinta, Claudia Metelli (Clodia): A construção de um mito no principado augustano", en Mulheres na Antiguidade, 2012, Rio do Janeiro, NEA/UERJ, p. 66.

${ }^{14}$ Sarah Fernandes Lino de Acevedo, História, retórica e mulheres no império romano, 2012, Ouro Preto, Editora UFOP, p. 59. 
lado en lo absoluto: el historiador también alabó las cualidades de Popea Sabina; de ella subrayó que no era lasciva, es decir, que nunca se dejó arrastrar por las bajas pasiones (Tac. Ann., 13, 45, 7). ${ }^{15}$ Con la descripción de las virtudes de Popea tenemos ante nosotros a una mujer que rompe con los esquemas y con los estereotipos romanos. Las mismas cualidades, de actitud estoica hacia las pasiones, las tenía Agripina, según nuestro historiador, al menos en los primeros tiempos de su matrimonio con Claudio.

\section{Descalificaciones contra los varones (por no comportarse como varones romanos)}

Los hombres también son igual o más pasionales y viscerales que las mujeres, según recoge Tácito en varios pasajes o anécdotas de su obra. Ahora veamos algunos de los actos que son más reprensibles en el grupo masculino, en tanto que parecen atentar contra la idea romana de "masculinidad". Y como dicen los teóricos de la historia de género (o los analistas del género en la historiografía), esos actos reprensibles nos son útiles porque es a través de las representaciones de los sexos que se puede

${ }^{15}$ Complete works of Tacitus, 1942, Nueva York, Random House. Disponible en: http://www. perseus.tufts.edu/hopper/text?doc $=$ Perseus $\% 3$ atext \%3a1999.02.0078. dar cuenta de las tensiones y las contradicciones al interior de una sociedad. ${ }^{16}$ Podemos así comprender otras razones por las cuales un historiador (antiguo) escribe (o parece escribir) benigna $u$ hostilmente sobre determinados hombres y mujeres.

El grupo de los varones gobernantes y aristocráticos de la Roma antigua desarrollaron durante los inicios del principado un papel bélico-masculino ${ }^{17}$ que los distinguía de sus también poderosas esposas, madres, hermanas o hijas. Veamos qué actitudes podían dañar ese rol masculino de acuerdo con Tácito.

1) El caer engañado por las veleidades de una mujer es un acto indigno para la masculinidad: Tácito nos cuenta que Octavio Sagita, por estar enamorado de Poncia, una mujer casada, dilapida su fortuna y logra que ella se divorcie. Pero luego, ella no consiente en casarse con él y, tras un arranque de furia bien planeado, la asesina. Un hombre como "víctima" de una mujer es pues un lugar común en los Anales.

Cayo Silio, el amante favorito de la emperatriz Mesalina, fue obligado a casarse bigámicamente por y con

${ }^{16}$ Lourdes Conde Feitosa, "Masculino e feminino na sociedade romana: Os desafios de uma análise de gênero", en Mulheres na Antiguidade, 2012, Rio do Janeiro, NEA/UERJ, 2012, p. 207.

${ }^{17}$ Stéphane Benoist, "Women and Imperium in Rome: Imperial Perspectives", en Jacqueline FabreSerris y Alison Keith (eds.), Women and war in antiquity, 2015, Baltimore, Johns Hopkins University Press, p. 266. 
ella. (Un acto que sería, finalmente, la causa de la perdición de ambos). Silio, famoso por su gallardía y su hermosura, era un joven en la época de sus amoríos con Mesalina y, pese a saber que estaría acostándose con la esposa del mismísimo emperador, consintió a los deseos matrimoniales de ella: tenemos el ejemplo de 2) un hombre que temía más a una mujer, la emperatriz, que a un hombre, el mismísimo emperador. Aquí cabe decir que la descripción de Mesalina como una mujer liberal y promiscua viene de una tradición que Tácito sigue, ${ }^{18}$ pero, sea falsa, cierta o exagerada esa cualidad de la emperatriz, lo cierto es que nuestro historiador también nos vuelve a mostrar el gran poder político que muchas romanas tuvieron. Un poder con el que podían manipular y de hecho manipulaban a los varones.

Dice Tácito sobre las acciones de Silio, el constreñido amante de Mesalina, que: "no ignoraba ni la acción vergonzosa ni el peligro; sin embargo, estando seguro de su ruina si se negaba, y con ciertas esperanzas de pasar inadvertido, y además con grandes recompensas, se consolaba disimulando lo que vendría más tarde y disfrutando el presente." (Tac. Ann., $11,12,2) \cdot{ }^{19}$ El miedo hacia Mesalina

${ }^{18}$ Christopher Lee Web, The death of Octavia: Tacitus' Annales 14.60-64 and the Octavia Praetexta, 2005, Georgia, University of Georgia, pp. 69-70.

${ }^{19}$ Tácito, Anales Libros XI-XII, trad. de José Tapia Zúñiga. era mayor que el miedo hacia el emperador Claudio, esta mujer era muy poderosa, en el sentido de poder imponer -independientemente del método - su voluntad sobre otros. Y en ese sentido quizá era más poderosa que la misma cabeza del imperio, Claudio. Pero esto solo es un caso: Livia ya se las había ingeniado para imponer a su hijo Tiberio como emperador (un asunto importante pues "el alcance de la participación de Livia en ese desarrollo [la llegada de Tiberio a la cabeza del Imperio] ha ocupado la posteridad durante dos mil años". ${ }^{20}$ )

Una muestra clara ya clásica del retrato de la debilidad en el género masculino lo encontramos en el emperador Claudio (10 a.C.-54 d.C.). El relato historiográfico que nos legó Tácito sobre tal emperador consiste en el dibujo de un ser que debía y necesitaba siempre estar sujeto a las mujeres. Lo anterior es una muestra de que, evidentemente, había hombres que necesitaban o requerían, al menos para la mentalidad taciteana, de 3) estar sujetos a una mujer; lo que puede significar que nuestro historiador no creía que la mujer era la única que debía estar o necesitaba estar sujeta al sexo opuesto. Los hechos históricos le comprobaban a Tácito la aseveración anterior.

Tácito dibujó a Claudio como un ser poco masculino al decirnos que era un individuo que necesitaba siempre

\footnotetext{
${ }^{20}$ Matthew Dennison, op. cit., p. 127.
} 
estar sujeto. Sobre la situación del emperador dice: "Con el asesinato de Mesalina, se perturbó la casa del príncipe, habiéndose levantado entre los libertos una contienda, sobre quién elegiría la esposa para Claudio, incapaz de soportar la vida de soltero y sometido a las órdenes de sus esposas." (Tac. Ann., 12, 1, 1). ${ }^{21}$ Es decir, eran otros miembros del género masculino, incluso podían ser libertos (en tanto que fueran varones), los que tenían que escogerle una esposa a aquel varón que era incapaz de buenas decisiones en esos asuntos, alguien que necesitaba siempre obedecer a una mujer. Y para un hombre que no era sino el emperador de Roma había que ser cuidadoso al escogerle una esposa: se decidió por Julia Agripina, la hija de Germánico — quien era nieto de Livia - - por ser la que, según decían, mejor podría ejercer un dominio o control sobre Claudio.

La continua mención de Augusto en los Anales se ha interpretado como el objetivo programático de Tácito de poner atención en el amplio cambio de la naturaleza estatal de Roma en aquella época y subrayar el interés de los sucesores de Augusto en institucionalizar tal cambio, ${ }^{22}$ lo cual puede estar vinculado con la descripción de Claudio como débil. Si

${ }^{21}$ Anales Libros XI-XII.

${ }^{22}$ Eleanor Cowen, "Tacitus, Tiberius and Augustus", Classical Antiquity 8/2 (2009), p. 206. el emperador Claudio era dominado por una mujer, era porque su antecesor, creador del principado, fue dominado por otra mujer: los sucesores de Octavio Augusto quizá tenían cierto interés, si no en institucionalizar, sí en hacer ver que el dominio de una mujer sobre el emperador era algo "normal".

Nuestro historiador nos provee de una esclarecedora anécdota para nuestra disquisición en torno a lo que era ser varón en el siglo I d.C.

$[\ldots]$ se procede al interrogatorio [de Valerio Asiático] en una habitación privada, en presencia de Mesalina, y mientras Suilio le echaba en cara la corrupción de los soldados, los cuales alegaba que habían sido sometidos con dinero y con la prostitución del cuerpo a toda clase de infamias, su adulterio con Popea y, en fin, lo afeminado de su persona. Ante esto, roto el silencio, el acusado [Asiático] estalló, y "pregunta, dijo, a tus hijos, Suilio; ellos te confesarán que soy un hombre". (Tac. Ann., 11, 2, 1). ${ }^{23}$

Lo que rescatamos de lo citado es que Valerio Asiático expresa, quizá principalmente porque se trata de un soldado y uno de alto rango, que 4) el varón romano (digno de respeto) no puede ni debe de prostituirse o vender su cuerpo y que, en caso de que lo

\footnotetext{
${ }^{23}$ Tácito, Anales Libros XI-XII.
} 
hiciera, se estaría rebajando a ser catalogado como mujer. Una opinión que no podemos asegurar que nuestro autor compartiera, pero que nos hace ver que lo peor que se podía decir sobre los soldados es que vendían su cuerpo: era otra enseñanza taciteana para la sociedad romana. Los soldados romanos eran la quintaesencia de la masculinidad, y esto es la causa de que Asiático estallara en ira contra Suilio al verse acusado de algún tipo de prostitución. El cónsul y líder militar no pudo más que recurrir a la buena o mala honestidad de los propios hijos de Suilio para salvar, al menos, su honor.

Haciendo una síntesis, tenemos cuatro tipos de descalificaciones contra los varones, que recoge Tácito: 1) Ser engañado y mentido por una mujer (comúnmente por causa del amor que se profese hacia la mujer, como el caso de Octavio Sagita); 2) ser controlado por una mujer (Cayo Silio); 3) necesidad de ser controlado por una mujer (el emperador Claudio); 4) Prostituirse (Valerio Asiático).

Las recriminaciones 1) y 4) son especialmente malas para la masculinidad en tanto que pueden significar la imposibilidad de controlar las pasiones amorosas o sexuales y, ya que el descontrol de las pasiones podía ser una cualidad feminizante en concreto, ello afectaba en mayor medida a la reputación del varón como varón.

\section{Una grave descalificación contra ambos géneros por igual: el incesto}

Existía una práctica que era mayoritariamente mal vista tanto por la sociedad romana como por su religión (durante prácticamente todo el periodo de la antigüedad): el incesto. La connotación de impureza que esta práctica tenía desempeñaba una función social que consistía en formar un grupo social evitando las prácticas endogámicas, porque estas pueden impedir el entendimiento y entrecruzamiento de los diversos miembros de la comunidad. ${ }^{24}$ La endogamia, en la forma de incesto, puede malograr el florecimiento de una comunidad.

Ni los argumentos de una de las filosofías helenísticas más sobresalientes, la cínica, hicieron que el incesto fuera bien visto en la antigüedad. Tenemos argumentos a favor del incesto como los siguientes: Diógenes de Sínope, en el siglo IV a.C., aludía que Edipo se quejaba en demasía de que su esposa fuera por igual su madre, y de que sus hijos fueran también sus hermanos; y aseveraba que a los perros, a los burros y demás animales, no les incomodaban tales situaciones. ${ }^{25}$ Pero las reivindicaciones del incesto no fructificaron; como

\footnotetext{
${ }^{24}$ Véase Walter Burkert, Greek Religion, 1994, Harvard, Harvard University Press.

${ }^{25}$ Marcel Detienne, La muerte de Dionisos, 1982, Madrid, Taurus, p. 122.
} 
en muchas ocasiones, las deliberaciones filosóficas no llegaron al pueblo llano, ni siquiera en tiempos del apogeo de tales deliberaciones, $\mathrm{y}$ mucho menos pudieron, en este caso, derribar prohibiciones ancestrales. Por el contrario, fueron los filósofos cínicos posteriores, de los siglos I a III d.C., que vivieron en el Imperio Romano, los que se adaptaron a las costumbres morales y sexuales de los griegos y romanos de esa época. Por ejemplo, el cínico Dion Crisóstomo condenó la homosexualidad en sus discursos para estar conforme con la homofobia de las clases bajas de su época. ${ }^{26}$

Los cínicos ortodoxos habían considerado a la homosexualidad como una práctica tan indiferente (para lograr el correcto comportamiento moral) como el incesto. Aunque hay que considerar que para el siglo II d.C. el cinismo era más un referente de la radicalidad de algunos filósofos que una filosofía plenamente viva, como se colige al compararlo con otras escuelas exitosas en aquella época como el caso del estoicismo y del platonismo. $^{27}$

En términos amplios, las costumbres (morales) grecorromanas eran difíciles de cambiar y, en el caso del

${ }^{26}$ W. Desmond, Cynics, 2008, Berkeley, University of California Press, p. 91.

${ }^{27}$ Michael Trapp, "Cynics", en Greek and roman philosophy 100 BC-200 AD, Vol. 1, 2007, Londres, University of London, p. 198. incesto, solo los poderosos, los dioses, podían hacer caso omiso, desde siempre, de los tabúes referentes a la susodicha práctica: Zeus o Júpiter cometieron múltiples incestos a lo largo de sus aventuras amorosas. El dios supremo está casado "oficialmente" con su misma hermana, Hera (o Juno). Pero estos, y más casos, son excepciones a la imperturbable e inexorable regla cotidiana de los griegos y de los romanos, y Tácito nos lo enseña en los Anales. Para el siglo I d.C. en Roma la acusación de incesto se convirtió en una fuerte herramienta para deshacerse de los indeseados y de los rivales políticos, tal acusación es común encontrarla en la obra taciteana.

Nos refiere Tácito: "Sexto Mario, el más rico de las Españas, acusado de haber cometido incesto con su propia hija, fue despeñado en la roca Tarpeya" (Tac. Ann., 6, 19, 1). ${ }^{28}$ Incluso el incesto cometido dentro de la familia imperial debe de ser explicado y, para continuar con el apoyo de los diversos grupos de poder, justificado: en otro pasaje taciteano se hace recaer la culpabilidad del incesto Nerón-Agripina en Agripina pero no porque se trate de una mujer $y$, como tal, de un ser al que se le considere siempre el responsable en estos asuntos (aquí de nuevo, no debemos de ver estereotipos "misóginos"

\footnotetext{
${ }^{28}$ Tácito, Anales.
} 
— valga el anacronismo- donde no los hay), sino porque se trata de una persona que fue pervertida alevosamente desde muy joven: "o porque Agripina hubiese concebido en su ánimo un deseo [incestuoso hacia su hijo] tan desordenado y tan contra la naturaleza, o porque cualquier apetito sensual es más creíble en una mujer que en los años de su niñez, movida del deseo de mandar, había consentido a los apetito deshonestos de Lépido" (Tac. Ann., 14, 2, 2). ${ }^{29}$ En otras palabras fue, al final de cuentas, un varón quien pervirtió a Agripina y en él también recae la responsabilidad.

Sin embargo, historiadores como Fabio Rústico y Suetonio (sin razón clara alguna) exoneraron a Agripina de su incesto con su hijo y culpan a éste de ser el incitador. ${ }^{30}$ Esto nos lleva a la premisa de que en Roma y Grecia solo a los poderosos se les pasaba por alto el quebrantamiento de ciertas normas morales, aunque a veces perdieran cierta legitimidad en su poder, pero en otras ocasiones ese quebrantamiento implicaba cierto valor positivo simbólico, de uso político, como nos hace ver Champlin:

[...] el incesto entre madre e hijo tenía una clara significación simbólica, y las historias sobre él comparten una

${ }^{29}$ Ibid.

${ }^{30}$ Edward Champlin, Nerón, 2008, México, FCE/Turner, trad. de Horacio Pons, p. 58. característica, a saber, que el héroe es o desea ser el conquistador de una patria de la cual en ese momento está de alguna manera excluido. La consulta de libros de sueños podía servir a los grandes hombres para cerciorarse de que sus madres simbolizaban su país [...] Conquistar a la propia madre era conquistar la tierra, madre de todos. ${ }^{31}$

Un caso que nos otorga Tácito, sobre el descrédito y pérdida de legitimidad al cometer incesto es el siguiente: “[Vitelio] comenzó a acusar criminalmente a Silano de sospecha de amores incestuosos con su hermana." (Tac. Ann., 12, 4, 1-2). ${ }^{32} \mathrm{La}$ anterior fue una acusación que levantó resquemores aún cuando fue muy infundada, es decir, nunca se corroboró el incesto de Silano, sin embargo, parece que su reputación quedó enlodada por siempre. Con la mera sospecha de incesto, una mujer o un hombre podían quedar mancillados permanentemente y hasta los poderosos podían caer en el desprestigio.

Aún a finales del siglo I d.C., infringir las prohibiciones sexuales era causa de duro castigo; Domiciano (51-96 d.C.) en el 87 d.C. acusa de incesto a la vestal máxima, en aquel año, Cornelia. Se trataba de una doble falta, primero contra el celibato que

\footnotetext{
${ }^{31}$ Ibid., p. 127.

${ }^{32}$ Tácito, Anales Libros XI-XII.
} 
juraban las vestales y segundo por el incesto en sí. Y el emperador Domiciano podía igualmente acusar con autoridad religiosa, porque en su época los emperadores también detentaban el cargo de pontífice máximo y otros cargos religiosos. Independientemente de si la acusación fuera verdad o una maquinación del emperador, el punto es que el gobernante estaba cumpliendo con su función de mantenedor de las costumbres (y la moral) religiosas, cumpliendo con su responsabilidad de preservar la unidad y salvación del pueblo romano mediante la piedad hacia los dioses.

Es sobresaliente la persistencia del tabú contra el incesto. Unas pocas décadas antes de Domiciano, el emperador Claudio, casado con su sobrina, ya había legalizado el casamiento entre tíos y sobrinos, no obstante Tácito nos dice que los romanos no realizaron nunca estas bodas salvo casos muy excepcionales (Tac. Ann. 12, 7, 1-3). Estas modificaciones legales no "aprovechadas", considero, indican que el pueblo de Roma tenía muy arraigadas sus costumbres y prejuicios contra el incesto. Séneca el Joven, conspicuo exponente y seguidor de la filosofía estoica, filosofía que también había defendido el incesto pues había nacido del cinismo, se había opuesto al incesto de Nerón con Agripina y, en una ocasión, para evitarlo en último momento, llamó a la amante del emperador, Acte, logrando momentáneamente calmar a Nerón en sus intenciones incestuosas. ${ }^{33}$

Vemos que no porque las clases altas realizaran ciertas acciones (incestuosas o adúlteras, por ejemplo), el pueblo llano las imitaba sin demora. Si el adulterio se puso de "moda" en el siglo I a.C. aproximadamente, y lo mismo el divorcio ("las facilidades para el divorcio habían, por así decirlo, legitimado por anticipado el adulterio"), ${ }^{34}$ el caso es que el incesto jamás encontró un lugar en la sociedad romana. Vamos, hay costumbres aprobadas por una sociedad, aunque disfrazadas y matizadas (adulterio), y hay otras que nunca se aceptarán (incesto). Lo anterior es exhibido en la obra taciteana (para seguimiento de los romanos).

\section{¿Roma moral y absolutamente decadente?}

Cabe decir que, pese a las múltiples anécdotas de vicios que se regala en los Anales, considero que el autor no aparece como un individuo que condene por completo tanto a las mujeres como a los hombres de la época

\footnotetext{
${ }^{33}$ Edward Champlin, op. cit., p. 110.

${ }^{34}$ Jérôme Carcopino, Daily life in ancient Rome,
} 1979, New Haven, Yale University Press, p. 95. 
imperial por conformar una sociedad "decadente" de una forma generalizada. Sabe que hay una cierta decadencia en el tiempo del Imperio Romano, cuando compara su época con la de la República, empero, como bien observa John Burrow ${ }^{35}$ en su análisis historiográfico de la obra de Tácito, éste no es plenamente fatalista pues intuye que los cambios (mejoramiento o empeoramiento) de los usos y costumbres dentro de una sociedad pueden ser cíclicos.

Tácito cree de forma optimista que los individuos decadentes de su época en algún momento desaparecerán $y$, que en un futuro, habrá alguna regeneración moral en Roma (desconozco cómo planteó Tácito que se lograría esto). Según podemos inferir a partir del estudio político de Raymond Mercado, ${ }^{36}$ los cambios descritos por el historiador no son una pendiente sino una oscilación entre la libertad y la esclavitud (metafórica) de Roma o una oscilación entre un régimen más o menos republicano y más o menos de principado. Y oscilantes son también las costumbres y la ética de cualquier sociedad.

La pendiente no es interminable: en algún punto la historia de Roma volverá a subir una colina, y esto es patente por el hecho de que Tácito aún encuentra actitudes encomiables en los habitantes y los dirigentes del Imperio, actitudes que servirán de ejemplo a las generaciones posteriores. Tácito no sólo encontró acciones reprobables sino también encomiables. Y el hecho de que muchos de estos ejemplos encomiables, los exempla, vengan de féminas (como Paulina o Popea), es muy significativo, pues muestra la amplitud de recursos (retóricos) de Tácito.

Si nuestro historiador tenía en mente cumplir con el propósito de hacer una investigación histórica sine ira et estudio entonces es coherente establecer, por la evidencia que otorga su texto, que nunca quiso construir un discurso lleno de odio o prejuicio ni contra las mujeres como grupo, ni contra los varones como grupo. Y, cuando nos encontramos con lo que pareciera ser una descalificación contra una mujer o contra un hombre hay que tener siempre cuidado: no hay que quedarnos con la idea de que todos los autores (varones) antiguos consideraban a la mujer como inferior, pasional, afeminada, etc., ni al varón como superior, circunspecto, valiente, etc.

\footnotetext{
${ }^{35}$ John Burrow, op. cit., p. 181.

${ }^{36}$ Raymond Mercado, "On Sedition in Tacitus", Perspectives on Political Science, 35/1 (2006), pp. 14-21.
} 
Se prohíbe su reproducción total o parcial por cualquier medio, incluido electrónico, sin permiso previo y por escrito de los editores. 